\title{
Marine Microbes: Unexplored Therapeutic Bio-mine
}

\section{Prakash S Bisen*}

Emeritus Scientist, Chief, Research and Development, Tropilite Foods Pvt. Ltd., Davars Campus, Tansen Nagar, Gwalior 474002, India

Whenever we focus our attention towards malignancies caused by cancer, usually our mind gets preoccupied with many conflicting thoughts. When we look at cancer statistics, our heart starts sinking more and more as we drill down to details about incidence rate, mortality rate, trends etc. In spite of tremendous technological advancements over several decades, cancer is second only to cardiovascular disease as a cause of death. When we see so many people dying from cancer, sometimes we wonder if this is a nature's answer to keep population under control. But when we bring together data from different sources like epidemiological studies, cancer molecular biology, molecular epidemiological studies; we are more than convinced that cancer is a man-made malignancy akin global warming.

In fact when we review source of drugs available for cancer treatment, it's inevitable to miss fact that majority of anticancer drugs are sourced either directly from natural bioactive compounds or after structural optimization of natural compound. We can say that nature holds bounty of medicinal compounds, and onus is on us to discover and explore their possible medicinal applications. Usage of compounds from natural sources especially plant based can be dated back to possibly even before dawn of civilization. Most of the chemotherapeutic drugs are also derived from natural bioactive compounds. Research effort during past several decades has been dedicated on screening of bioactives from natural sources, with more focus on easily available resources like terrestrial fauna and flora. However, big pharmaceutical companies have diverted their focus from natural compound based discovery most probably to avoid possible patent conflicts.

'Sea holds many secrets' is a line of poem Iron Coffins by David Harris, which aptly applies for unexplored marine biodiversity and novel medicinal compounds spread across marine flora and fauna. To start this exploration, scientist can just surf over aquatic sources to discover therapeutically important entities, and then start deep diving in pursuit of unexplored biological treasures with endless possibilities. Cynobacteria is one of such marine microbe which is ubiquitously found in fresh water and marine ecosystem.

Cynobacteria are one of the richest sources of known and novel bioactives. Siprulina genus of cynobacteria group is well known for its nutritional and therapeutic value [1,2]. Some of the potential lead compounds with anticancer activities include curacin A, symplostatin 3, belamide A, dolastatin 10, halichondrin B. Nostoc linckia and Nostoc spongiaeforme are marine strains of cynobacteria, which is source of borophycin a boron containing metabolite. Borophycin has demonstrated cytotoxicity against human colorectal adenocarcinoma cell lines and human epidermoid carcinoma [3,4]. Cryptophycin isolated from Nostoc sp. has also demonstrated potent cytotoxicity against human tumor cell lines [5,6]. Antiproliferative action of cryptophycin is due to its interaction with tubulin [7-9]. C-Phycocyanin is yet another potential anti-cancer compound present abundantly in cynobacteria. C-Phycocyanin has been demonstrated to inhibit proliferation of human hepatoma cell line (HepG2) [10], and induces apoptosis by selective activation of caspase- 3 , inhibition of bcl-2 and generation of reactive oxygen species [11]. C-Phycocyanin is known to selectively inhibit COX-2 [12]. COX-2 is significantly expressed in various cancers including breast cancer, therefore c-phycocyanin holds potential to become anti-cancer compound. Cyanobacterial cyclopeptides like microcystins have potential to induce apoptosis and their propensity to be taken up via Organic Anion Transporting Polypeptides (OATP) which are expressed more in metastatic cancer cells compared with normal cells make them potential anti-cancer drug candidates [13-15]. Some of potent compounds from cyanobacteria with anti-cancer activities which have garnered interest in recent years are largazole [16] and apratoxin [17].

In this write-up I have briefly discussed just one group from the rich marine biodiversity, with lot other still waiting to be explored. Drug discovery efforts centered on marine microbes, also makes good business sense for big pharmaceutical companies, they can look this as an opportunity to enrich their pipeline which of late is drying soon. Fight against cancer has been unnerving like a long and dark night, but we should hope Mother Nature will guide us through this difficult phase, as it has done time and again. Mesmerized with great biodiversity in nature, I conclude this write-up with a sense of optimism that our scientific endeavors would make world better place for generations to come.

\section{References}

1. Khan Z, Bhadouria P, Bisen PS (2005) Nutritional and therapeutic potential of Spirulina. Curr Pharm Biotechnol 6: 373-379.

2. Kulshreshtha A, Zacharia AJ, Jarouliya U, Bhadauriya P, Prasad GB, et al. (2008) Spirulina in health care management. Curr Pharm Biotechnol 9: 400405

3. Banker R, Carmeli S (1998) Tenuecyclamides A-D, cyclic hexapeptides from the cyanobacterium Nostoc spongiaeforme var. tenue. J Nat Prod 61: 12481251.

4. Davidson BS (1995) New dimensions in natural products research: cultured marine microorganisms. Curr Opin Biotechnol 6: 284-291.

5. Moore RE (1996) Cyclic peptides and depsipeptides from cyanobacteria: a review. J Ind Microbiol 16: 134-143.

6. Carmichael WW (1992) Cyanobacteria secondary metabolites--the cyanotoxins J Appl Bacteriol 72: 445-459.

7. Panda D, Himes RH, Moore RE, Wilson L, Jordan MA (1997) Mechanism of action of the unusually potent microtubule inhibitor cryptophycin 1 . Biochemistry 36: 12948-12953.

8. Panda D, DeLuca K, Williams D, Jordan MA, Wilson L (1998) Antiproliferative mechanism of action of cryptophycin-52: kinetic stabilization of microtubule dynamics by high-affinity binding to microtubule ends. Proc Natl Acad Sci U S A 95: 9313-9318.

*Corresponding author: Prakash S. Bisen, Ph.D., Emeritus Scientist, Chie Research and Development, Tropilite Foods Pvt. Ltd., Gwalior 474002, India, E-mail: psbisen@gmail.com

Received July 30, 2012; Accepted August 01, 2012; Published August 03, 2012

Citation: Bisen PS (2012) Marine Microbes: Unexplored Therapeutic Bio-mine. J Cancer Sci Ther 4: xviii-xix. doi:10.4172/1948-5956.1000e112

Copyright: ( 2012 Bisen PS. This is an open-access article distributed under the terms of the Creative Commons Attribution License, which permits unrestricted use, distribution, and reproduction in any medium, provided the original author and source are credited. 
9. Panda D, Ananthnarayan V, Larson G, Shih C, Jordan MA, et al. (2000) Interaction of the antitumor compound cryptophycin-52 with tubulin Biochemistry 39: 14121-14127.

10. Bashaf OM, Hafez RA, El-Ayouty YM, Mahrous KF, Bareedy MH, et al. (2008) C-Phycocyanin inhibits cell proliferation and may induce apoptosis in human HepG2 cells. Egypt J Immunol 15: 161-167.

11. Pardhasaradhi BV, Ali AM, Kumari AL, Reddanna P, Khar A (2003) Phycocyanin-mediated apoptosis in AK-5 tumor cells involves down-regulation of $\mathrm{Bcl}-2$ and generation of ROS. Mol Cancer Ther 2: 1165-1170.

12. Reddy MC, Subhashini J, Mahipal SV, Bhat VB, Srinivas Reddy P, et al. (2003) C-Phycocyanin, a selective cyclooxygenase-2 inhibitor, induces apoptosis in lipopolysaccharide-stimulated RAW 264.7 macrophages. Biochem Biophys Res Commun 304: 385-392.

13. Monks NR, Liu S, Xu Y, Yu H, Bendelow AS, et al. (2007) Potent cytotoxicity of the phosphatase inhibitor microcystin LR and microcystin analogues in OATP1B1- and OATP1B3-expressing HeLa cells. Mol Cancer Ther 6: 587-598.

14. Herfindal L, Kasprzykowski F, Schwede F, Łankiewicz L, Fladmark KE, et al. (2009) Acyloxymethyl esterification of nodularin-R and microcystin-LA produces inactive protoxins that become reactivated and produce apoptosis inside intact cells. J Med Chem 52: 5758-5762.

15. Sainis I, Fokas D, Vareli K, Tzakos AG, Kounnis V, et al. (2010) Cyanobacteria cyclopeptides as lead compounds to nofvel targeted cancer drugs. Mar Drugs 8: 629-657.

16. Hong J, Luesch H (2012) Largazole: from discovery to broad-spectrum therapy Nat Prod Rep 29: 449-456.

17. Chen QY, Liu Y, Luesch H (2011) Systematic Chemical mutagenesis identifies a potent novel apratoxin A/E hybrid with improved in vivo antitumor activity. ACS Med Chem Lett 2: 861-865. 